AT-TAJDID: Jurnal Pendidikan Dan Pemikiran Islam

(p-ISSN: 2548-5784 |e-ISSN: 2549-2101)

Vol. (04 )(01), (Januari-Juni) (2020), (Halaman)(38-45)

Doi: http://dx.doi.org/10.24127/att.v4i01.1214

\title{
PENGEMBANGAN KURIKULUM PENDIDIKAN AGAMA ISLAM DI SMA IT ABU BAKAR YOGYAKARTA
}

\author{
Dwi Noviatul Zahra \\ UIN Sunan Kalijaga Yogyakarta \\ dwinoviatulzahra11@gmail.com
}

\begin{abstract}
Abstrak
Penelitian ini bertujuan untuk mendeskripsikan pengembangan kurikulum Pendidikan Agama Islam di SMA IT Abu Bakar Yogyakarta. Kurikulum Pendidikan Agama Islam di sekolah umum perlu dikembangkan agar mampu menjawab tantangan zaman. Penelitian ini dilakukan dengan kajian bibiliografi dan wawancara. Hasil penelitian ini menemukan bahwa pengembangan kurikulum PAI di SMA IT Abu Bakar Yogyakarta mengintegrasikan tiga lingkungan pendidikan (sekolah, keluarga dan masyarakat), serta sains dengan ajaran Islam (khususnya Islam versi manhaj tarbiyah). Walau menggunakan KTSP, kurikulum PAI di SMA IT Abu Bakar Yogyakarta tetap mengacu pada kurikulum PAI Jaringan Sekolah Islam Terpadu (JSIT), dan berlandaskan ajaran manhaj tarbiyah. Hal ini tercermin dalam komponen materi kurikulum , misalnya, yang mengandung muwāshafat/kifāyah tarbawiyyah, dan juga seperti dalam komponen metode yang menggunakan pendekatan keteladanan.
\end{abstract}

Kata kunci: Pengembangan Kurikulum, Pendidikan Agama Islam

\begin{abstract}
This study aims to describe the curriculum development of Islamic Religious Education at SMA (Senior High School) IT (Integrated Islam) Abu Bakar Yogyakarta. Islamic Religious Education curriculum in non-madrasah schools needs to be developed in order to be able to answer the challenges. This research was conducted with a bibiliographic study and interviews. The results of this study found that the curriculum development of the Islamic Religious Education (PAI) at SMA IT Abu Bakar Yogyakarta integrated three educational environments (school, family and community), as well as science with Islamic teachings (specifically the version of Manhaj Tarbiyah Islam). Despite using KTSP curriculum, it still refers to the PAI curriculum of the Integrated Islamic Schools Network (JSIT), and is based on the teachings of Manhaj Tarbiyah. This is reflected in the curriculum material component, for example, which contains muwāshafat / kifāyah tarbawiyyah, and also as in the component method that uses the exemplary approach.
\end{abstract}

Keywords: Curriculum development, Islamic Religious Education

\section{A. PENDAHULUAN}

Pendidikan agama dipandang memiliki peranan yang sangat vital dalam membangun watak dan peradaban bangsa yang bermartabat. Untuk itu, diperlukan pengembangan 
pendidikan agama yang lebih kondusif dan prospektif terutama di sekolah atau perguruan tinggi. Model pengembangannya perlu direkonstruksi, dan model yang bersifat dikotomik dan mekanisme ke arah model organisme atau sistemik, model Pendidikan yang integral. Hanya saja untuk merombak model tersebut diperlukan kemampuan dan political will dari para pengambil kebijakan, termasuk di dalamnya para pimpinan lembaga pendidikan itu sendiri (Nurlaila 2011).

Pendidikan agama yang terus berusaha mencari jati dirinya di antaranya adalah pendidikan agama Islam. Belakangan ini, bermunculan sekolah umum yang memadukan keilmuan umum dan keilmuan keislaman dalam bentuk sekolah Islam terpadu. Sekolah Islam Terpadu adalah sekolah yang diselenggarakan dengan memadukan secara integratif ajaran dan nilai-nilai luhur agama Islam dalam struktur kurikulum dengan menggunakan pendekatan pembelajaran efektif dan efsien, yang mengedepankan keseimbangan pencapaian aspek kognitif, afektif, dan psikomotorik melalui pelibatan yang optimal dan kooperatif (koordinatif, konsultatif, sinkronisasi) antara sekolah (terutama guru), keluarga (orang tua), dan masyarakat dalam membangun karakter dan kompetensi yang harus dimiliki peserta didik (Suprapto 2014).

Pendidikan Sekolah Islam Terpadu yang berkembang di masyarakat meliputi semua jenjang pendidikan, yaitu mulai dari sekolah dasar (SD IT), sekolah menengah pertama (SMP IT), sampai sekolah menengah atas (SMA IT). Sebagian sekolah tersebut dilabeli dengan sebutan Islam Terpadu (IT), namun ada juga yang tanpa dilabeli dengan tulisan IT, kendati di dalam penyelenggaraan pendidikannya melaksanakan pengintegrasian pendidikan agama ke dalam semua aspek pendidikan.

Sekolah Islam terpadu tentunya membawa wajah baru Pendidikan Agama Islam. Untuk itu perlu kiranya suatu kajian tentang pengembangan kurikulum PAI di sekolah Islam terpadu agar khazanah Pendidikan Agama Islam bertambah luas. Berdasarkan latar belakang tersebut, disusun lah penelitian ini. Dipilihnya SMA IT Abu Bakar Yogyakarta karena SMA IT Abu Bakar Yogyakarta merupakan sekolah Islam terpadu yang cukup lama berdiri, yaitu sejak 2003. Sehingga tentunya sudah berpengalaman dalam mengelola pendidikan, termasuk kurikulum.

\section{B. METODE PENELITIAN}

Penelitian ini merupakan penelitian lapangan kualitatif deskriptif. Data dikumpulkan dengan menggunakan metode wawancara semi terpimpin dan kajian bibiliografi. Adapun narasumber dalam wawancara yang dilakukan adalah Guru PAI. Wawancara digunakan untuk mengumpulkan data pengembangan kurikulum PAI. Sedangkan kajian bibiliografi digunakan untuk mengumpulkan mengumpulkan data pengembangan kurikulum PAI. 


\section{PEMBAHASAN}

\section{Landasan Teori}

Sebelum menuju pada hakikat pengembangan kurikulum Pendidikan Agama Islam (PAI), maka alangkah baiknya diketahui hakikat pengembangan kurikulum terlebih dahulu. Oemar Hamalik berpendapat bahwa pengembangan kurikulum adalah proses perencanaan kurikulum agar menghasilkan rencana kurikulum yang luas dan spesifik (Hamalik 2016). Proses pengembangan kurikulum tersebut berhubungan dengan seleksi dan pengorganisasian berbagai komponen situasi belajar-mengajar. Adapun pengembangan kurikulum dalam pandangan Muhaimin dapat diartikan sebagai suatu kegiatan yang menghasilkan kurikulum, atau proses yang mengaitkan satu komponen dengan komponen lainnya untuk menghasilkan suatu kurikulum yang baik, atau kegiatan penyusunan, implementasi dan evaluasi serta kegiatan perbaikan dan penyempurnaan kurikulum (Muhamimin 2013). Dari dua pendapat di atas, dapat disimpulkan bahwa pengembangan kurikulum adalah kegiatan penyusunan, implementasi dan evaluasi serta kegiatan perbaikan dan penyempurnaan kurikulum.

Sementara itu, Pendidikan Agama Islam (PAI) menurut Zakiyah Darajat adalah usaha berupa bimbingan dan asuhan terhadap anak didik agar setelah selesai dari pendidikannya dapat memahami dan mengamalkan ajaran agama Islam serta menjadikannya sebagai pandangan hidup (way of life) (Daradjat 2017). Secara lebih rinci, menurut Abdul Majid Pendidikan Agama Islam adalah upaya sadar dan terencana dalam menyiapkan peserta didik untuk mcengenal, memahami, menghayati, hingga mengimani ajaran Islam, dibarengi dengan tuntunan untuk menghormati penganut agama lain dalam hubungannya dengan kerukunan antar umat beragama hingga terwujud kesatuan dan persatuan bangsa (Hasan 2017).

Pengembangan kurikulum PAI menurut Muhaimin adalah kegiatan menghasilkan Kurikulum PAI dengan mengaitkan satu komponen dengan komponen lainnya berupa kegiatan penyusunan (desain), pelaksanaan, penilaian dan penyempurnaan kurikulum PAI untuk menghasilkan Kurikulum PAI yang lebih baik (Muhamimin 2013). Jadi, pengembangan kurikulum PAI bisa diartikan sebagai kegiatan penyusunan, implementasi dan evaluasi serta kegiatan perbaikan dan penyempurnaan kurikulum PAI.

Pengembangan kurikulum dilakukan di beberapa tingkat sebagai berikut.

a. Tingkat Makro, yaitu tingkat nasional dan mencakup Tri pusat pendidikan

b. Tingkat institusi, yaitu tingkat sekolah

c. Tingkat mata pelajaran, yaitu penyusunan silabus oleh kelompok musyawarah guru matapelajaran (MGMP), pusat kegiatan guru (PKG), 
d. Tingkat pembelajaran di kelas, yaitu penyusunan program pembelajaran oleh guru, seperti paket modul, paket belajar, paket berprogram dan rencana pelaksanaan pembelajaran (RPP) (Arifin 2013).

Dalam penelitian ini, pengembangan kurikulum yang dimaksud adalah pengembangan kurikulum pada tingkat mata pelajaran.

\section{Selanjutya,} kurikulum memiliki beberapa komponen yang slaing terikat satu sama lain. Menurut Nasution yang dikutip oleh Abdullah, komponen kurikulum ada empat yaitu tujuan, bahan pelajaran, proses, dan penilaian (Lnaggulung 2002). Sementara itu Hasan Langgulung membagi komponen kurikulum menjadi empat juga yaitu: tujuan pendidikan, isi atau kandungan pendidikan, metode pengajaran, dan metode penilaian (Abdulloh, 2010).

Sehingga dalam mini riset ini pengembangan kurikulum PAI dilaporkan sebagai berikut.

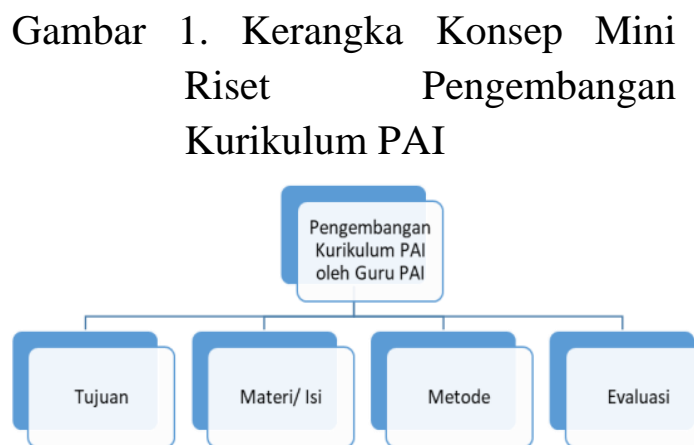

\section{Hasil Penelitian dan Pembahasan}

Kurikulum yang digunakan di SMA IT Abu Bakar Yogyakarta adalah Kurikulum Tingkat Satuan Pendidikan (KTSP). Undang-Undang No. 20 tahun 2003 bab I pasal 1 point (15), menyatakan, "KTSP adalah kurikulum operasional yang disusun oleh dan dilaksanakan di masing-masing satuan pendidikan." Jadi, dalam KTSP sekolah diberikan keluwesan untuk mengembangkan kurikulum (Kande 2008, 80). Dalam prakteknya, guru PAI di SMA IT Abu Bakar Yogyakarta tidak menyusun silabus sendiri, tetapi menggunakan silabus dari pemerintah dan diintegrasikan dengan silabus yang terdapat pada kurikulum PAI Jaringan Sekolah Islam Terpadu (JSIT). Kurikulum JSIT merupakan kurikulum Nasional 2004 yang menekankan pada pencapaian target kompetensi daripada materi, dan dikembangkan sesuai dengan kebutuhan, dalam rangka mencapai tujuan pendidikan di Sekolah Islam Terpadu (Tim Penyusun JSIT 2006, 2).

\section{Gambar 1. Dokumen Kurikulum JSIT}

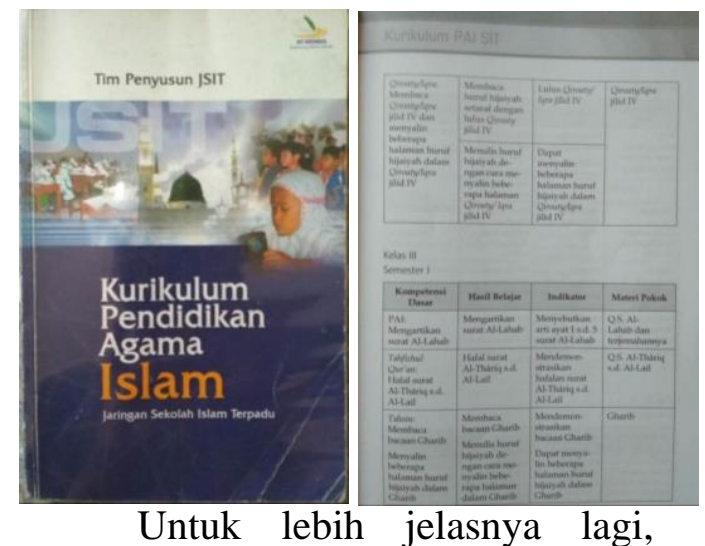

maka pengembangan kurikulum PAI di SMA IT Abu Bakar Yogyakarta dibahas dalam empat aspek, yaitu tujuan, materi, metode dan penilaian.

Tujuan PAI di SMA IT Abu Bakar Yogyakarta disesuaikan dengan tujuan sekolah. Dalam JSIT disebutkan bahwa tujuan PAI di Sekolah Islam Terpadu adalah menumbuhkan dan Copyright (C) 2020, Universitas Muhammadiyah Metro| 41 
meningkatkan keimanan melalui pemberian dan pemupukan pengetahuan, penghayatan, pengamalan, serta pengalaman siswa tentang agama Islam sehingga menjadi manusia muslim yang utuh (syakhsiyah Islamiyah mutakamilah) dan dapat melanjutkan pendidikan yang lebih tinggi (Tim Penyusun JSIT, 2006).

Adapun fungsi PAI di sekolah Islam terpadu adalah sebagai berikut.

1) Penanaman nilai;

2) Pengembangan keimanan dan ketakwaan;

3) Penyesuaian mental;

4) Perbaikan kesalahan-kesalahan;

5) Pencegahan dari hal-hal yang negatif;

6) Pengajaran ilmu Allah (kauniyah, qauliyah, gaib, nyata)

7) Persiapan untuk mendalami pendidikan agama ke lembaga yang lebih tinggi (Tim Penyusun JSIT 2006).

Secara garis besar ruang lingkup materi PAI di SMA IT Abu Bakar Yogyakarta adalah al-Quran, alhadits, akidah, akhlak, ibadah/ fikih dan tarikh/ sejarah Kebudayaan Islam (Tim Penyusun JSIT 2006, 4). Dalam pengembangannya, materi PAI tersebut dikombinasikan dengan materi gerakan tarbiyah, yaitu muwāshafat/kifāyah tarbawiyyah (kompetensi tarbawi), sebagai berikut.
1) Salimul 'Aqidah: 'Akidah yang benar
2) Shohihul 'Ibadah: Ibadah yang benar
3) Matinul Khuluk: Akhlak yang mapan

4) Qadiru 'ala al-kasbi: Kemampuan berusaha/ bekerja

5) Mutsaqaful fikri: Bekal pemikiran/ wawasan

6) Qawiyul Jismi: Jasad yang kuat

7) Mujahidun Linafsi: Kesungguhan diri

8) Munazzam fi Syu'nihi: Manajemen diri

9) Harisun 'ala Waqtihi: Manajemen waktu

10) Naafi'un

Liqhairihi:

Bermanfaat untuk orang lain (Nurjamilah, 2014).

$\begin{array}{ccr} & \text { Sepuluh program tersebut } \\ \text { menjadi } & \text { landasan } & \text { dalam }\end{array}$ pengembangan materi PAI. Sehingga meskipun menggunakan buku siswa PAI terbitan Eirlangga sebagai bahan ajarnya misalnya, guru mengembangkan materi PAI sedemikian rupa agar tetap sesuai dengan sepuluh program tersebut. Pentingnya pengkombinasian materi PAI dengan muwāshafat/kifāyah tarbawiyyah ini didukung dengan wajibnya guru mengikuti program halaqah setiap seminggu sekali. Di dalam halaqah tersebut guru ditingkatkan kualitas mengajarnya, termasuk pendalaman muwāshafat/kifāyah tarbawiyyah.

Gambar 2. Buku Ajar PAI SMA IT Abu Bakar Yogyakarta

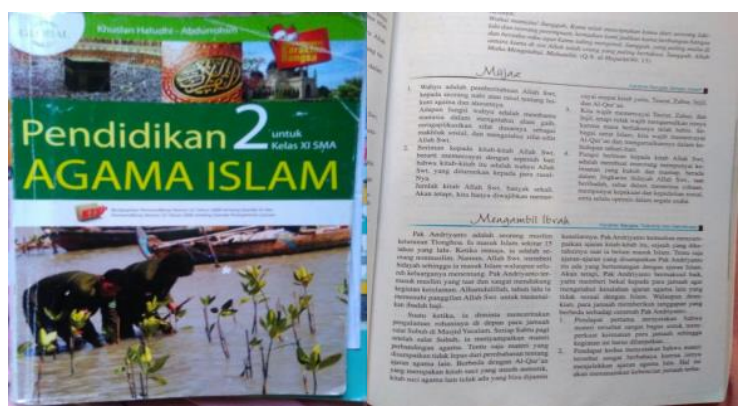

Copyright (C) 2020, Universitas Muhammadiyah Metro| 42 


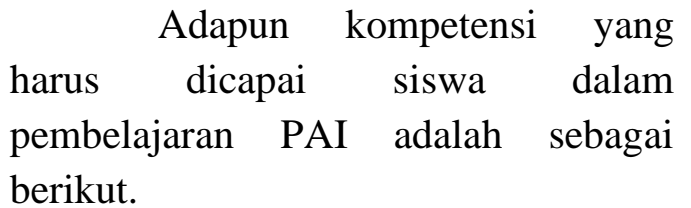

1) Siswa mampu membaca al-Quran sesuai dengan tajwid dan muratal standar; menambah hafalan dua juz al-Quran, yaitu juz 26 dan juz 1; memahami arti, tafsir, dan asbabun nuzul beberapa surat atau ayat tematik sains dan sosial, mendeskripsikan kedudukannya, serta mengamalkannya dalam kehidupan sehari-hari.

2) Siswa mampu membaca, mengartikan, menghafal, menyalin, memahami, dan mengamalkan doadoa al-Ma'tsurat dan 15 hadits dari Arba'in Nawawi, serta mengamalkannya dalam kehidupan sehari-hari.

3) Siswa mampu menerapkan akidah islamiah.

4) Siswa mampu menerapkan akhlakul karimah.

5) Siswa mampu menerapkan syariat/ hukum-hukum Islam.

6) Siswa mampu menggambarkan tarikh Islam sebagai ekspresi pengalaman ajaran Islam terutama tentang peradaban Islam sejak pasca-Khulafaur Rasyidin sampai tumbuhnya gerakan-gerakan dakwah Islam yang berskala nasional maupun internasional (Tim Penyusun JSIT, 2006).

Dalam pengorganisasian materi, terdapat beberapa hal yang harus diperhatikan, baik oleh guru PAI maupun non PAI.
1) Sesuai dengan prinsip didaktik, yaitu dari mudah ke sulit, sederhana ke kompleks, dan dari konkret ke abstrak.

2) Mengandung nilai-nilai yang terkait dengan perilaku kehidupan seharihari.

3) Mengedepankan askep sikap yang dibalut dengan cerita tentang Nabi dan Rasul.

4) Keterpaduan tiga lingkungan pendidikan (keluarga, sekolah, masyarakat), dan keterpaduan dengan pelajaran lain.

Metode yang digunakan dalam pembelajaran PAI di SMA IT Abu Bakar Yogyakarta tidak jauh berbeda dengan sekolah lain pada umumnya. Hanya saja lebih diutamakan penggunaan pendekatan keteladanan. Secara lebih detail pendekatan pembelajaran PAI di SMA IT dijelaskan dalam kurikulum PAI JSIT sebagai berikut.

1) Keteladanan, seluruh guru menjadi teladan bagi siswa;

2) Pembiasaan, guru memberikan kesempatan siswa untuk membiasakan sikap dan perilaku yang sesuai dengan ajaran Islam dan budaya bangsa;

3) Nasihat, pendidik memberikan pemahaman kepada siswa bahwa tentang Islam secara utuh;

4) Perhatian, guru memberikan perhatian pada perkembangan peserta didik;

5) Hadiah dan hukuman, diberikan sesuai dengan situasi dan kondisi, dan dalam rangka memotivasi siswa 
agar tetap berada dalam adab Islam

(Tim Penyusun JSIT, 2006).

Pembelajaran madah diniyah yang bersifat tsaqafiyah dilakukan secara formal klasikal dalam pelajaran PAI dan secara kelompok untuk tahfizh, qiroaty, dan tahsin. Sementara itu, madah yang bersifat ruhiyah, tathbiqiyah dilakukan secara tidak formal, antara lain mutaba'ah syiar ibadah harian, muroja'ah qiraaty tahfizh dan tahsin, halaqah, mabit, bimbingan wudhu dan shalat berjama'ah, usbu' ruhi, gerakan infak, dan munasharah yang melibatkan tidak hanya guru PAI, tetapi seluruh SDM sekolah (Tim Penyusun JSIT, 2006).

Secara teknis, pembelajaran tahfizh, qiroaty, dan tahsin dipisahkan dari PAI. Pembelajaran PAI terbatas tiga jam dalam sepekan sesuai dengan kurikulum nasional. Sementara itu tahfizh, qiroaty, dan tahsin dilaksanakan secara fleksibel sesuai dengan ketersediaan waktu. Hal tersebut mengingat bahwa secara umum sistem full day school atau boarding school memiliki jumlah jam pelajaran relatif lebih banyak daripada tuntunan kurikulum nasional (Tim Penyusun JSIT, 2006).

Penilaian PAI di SMA IT Abu

Bakar Yogyakarta mengacu pada KTSP. Penilaian sikap lebih diutamakan dalam pembelajaran PAI, tentunya tanpa mengesampingkan aspek pengetahuan dan keterampilan. Aspek sikap merupakan penentu kenaikan siswa. Nilai terendah untuk aspek sikap adalah $\mathrm{C}$ dari interval A-D. Di dalam rapor, nilai sikap berada di awal halaman sebelum nilai kognitif dan psikomotorik. Hal ini menunjukkan betapa besarnya perhatian SMA IT Abu Bakar Yogyakarta pada askep sikap siswa.

Penilaian dilakukan secara terus-menerus dan menyeluruh, tidak hanya tes formal, tetapi juga pengamatan terhadap perilaku, sikap, mutabaah ibadah harian, mutabaah tilawah dan tahfizul Quran, dan berbagai pengamatan terutama tentang perilaku yang ekstrem atau kelainan pertumbuhan, diikuti dengan langkah bimbingan dan komunikasi sekolah dengan orang tua (Tim Penyusun JSIT, 2006).

\section{SIMPULAN}

Pengembangan kurikulum PAI di SMA IT Abu Bakar Yogyakarta mengintegrasikan tiga lingkungan pendidikan (sekolah, keluarga dan masyarakat), serta sains dengan ajaran Islam (khususnya Islam versi manhaj tarbiyah). Walau menggunakan KTSP, kurikulum PAI di SMA IT Abu Bakar Yogyakarta tetap mengacu pada kurikulum PAI Jaringan Sekolah Islam Terpadu (JSIT), dan berlandaskan ajaran manhaj tarbiyah. Hal ini tercermin dalam komponen materi kurikulum, misalnya, yang mengandung muwāshafat/kifāyah tarbawiyyah. Dalam komponen metode menggunakan pendekatan keteladanan. Bila diamati lebih jauh, kerapian yayasan Abu Bakar dan sistem pendidikan sekolah Islam terpadu lah yang menjadi kunci sukses SMA IT Abu Bakar Yogyakarta. Meski 
menggunakan KTSP, ideologi yayasan mereka tetap tertanam pada siswa dengan baik.

\section{E. DAFTAR PUSTAKA}

\section{Buku}

Abdulloh. (2010). Pengembangan Kurikulum Teori dan Praktek, Yogyakarta: Ar-ruzz Media.

Arifin, Zainal. (2013). Konsep dan

Model Pengembangan

Kurikulum, Bandung: Remaja Rosdakarya.

Daradjat, Zakiah. Ilmu Pendidikan Islam, cet. Ke-13. 2017. Jakarta: RajaGrafindo Persada.

Hamalik, Oemar. (2016). Dasar-Dasar Pengembangan Kurikulum, cet. Ke-6. Bandung: PT remaja Rosda Karya.

Langgulung, Hasan. (2002). Peralihan Paradigma Pendidikan Islam dan Sains Sosial, Jakarta: Gaya Media Pratama.

Muhaimin. (2013). Pengembangan Kurikulum Pendidikan Agama Islam di Sekolah, Madrasah dan Perguruan Tinggi. Jakarta: Raja Grafindo Persada.

Tim Penyusun JSIT. (2006). Kurikulum Pendidikan Agama Islam Jaringan Sekolah Islam Terpadu. Syaamil Cipta Media: Bandung.

\section{Jurnal}

Hasan, Moch. Sya'roni. (2017) "Pengembangan Kurikulum Pendidikan Agama Islam
Terpadu Di Sekolah", Jurnal, AlIbrah|Vol. 2 No. 1.

Kande, Fredrik A. (2008). "Membedah Kekuatan dan Kelemahan KTSP(Antara Globalisasi Lokal dan Ancaman Disintegrasi Bangsa)", Jurnal, Manajemen Pendidikan, No. 02/Th IV.

Nurjamilah, Cucu. (2014). "Keunikan Dakwah Halaqah Tarbiyah: Studi Pada Halaqah Tarbiyah PKS", Jurnal, Al-Hikmah, Vol. 8, No. 1.

Nurlaila. (2011). "Model-Model Pengembangan Pendidikan Agama Islam di Sekolah/ Perguruan Tinggi Umum". Jurnal, Ta'dib: Jurnal Pendidikan Islam IAIN Raden Fatah. Vol. 16 No. 2.

Soleh, Febrian Taufiq. (2015). "Manhaj Tarbiyah dalam Pendidikan Politik Kader Partai Keadilan Sejahtera (PKS)", Jurnal, SALAM Volume 18 No. 1, Malang, Juni 2015.

Suprapto. (2014). "Model Kurikulum Pendidikan Agama Islam di Sdit Al-Anwar dan Firdaus Mojokerto Jawa Timur". Jurnal, EDUKASI Volume 12, Nomor 1, JanuariApril. 